\title{
The Moral Conditions of Economic Efficiency
}

Walter J. Schultz

Cedarville University

Follow this and additional works at: https://digitalcommons.cedarville.edu/faculty_books

Part of the Behavioral Economics Commons, and the Economic Theory Commons

\section{Recommended Citation}

Schultz, Walter J., "The Moral Conditions of Economic Efficiency" (2001). Faculty Books. 93.

https://digitalcommons.cedarville.edu/faculty_books/93

This Book is brought to you for free and open access by DigitalCommons@Cedarville, a service of the Centennial Library. It has been accepted for inclusion in Faculty Books by an authorized administrator of DigitalCommons@Cedarville. For more information, please contact digitalcommons@cedarville.edu. 


\section{The Moral Conditions of Economic Efficiency}

\section{Description}

Schultz illustrates the deficiencies of theories that purport to show that markets alone can provide the basis for efficiency. He argues that markets are not moral-free zones, and that achieving the economic common good does indeed require morality. He demonstrates that efficient outcomes of market interaction cannot be achieved without moral normative constraints and then goes on to specify a set of normative conditions that make these positive outcomes possible.

\section{Disciplines}

Behavioral Economics | Economics | Economic Theory

\section{Publisher}

Cambridge University Press

\section{ISBN}

0521801788 


\section{Contents}

Preface and Acknowledgments

page $\mathrm{xi}$

1 Introduction and Synopsis

Morality, Moral Rules, and Normative Constraints

Synopsis of the Book

2 A Contextualized Proof of the First Fundamental Theorem of Welfare Economics

A Framework for Analyzing Social Situations $\quad 16$

Strict Rational Egoism

A Proof of the First Fundamental Theorem of Welfare

Economics

26

Other Definitions $\quad 28$

Summary Discussion

3 The Moral Thesis: Moral Normative Constraints Are

Necessary Conditions of Pareto-Optimal Equilibrium

Allocations of Commodities Achieved through Market

Interaction

33

Alternative Explanations for Price-Taking Behavior

The Presumption against Nonmarket Action Entails

a Contradiction

Perfectly Competitive Markets Cannot Ensure Competitive

Behavior

Maximal Information-Processing Capabilities and

Perfect Information Are Not Sufficient for Pareto-Optimal

Equilibrium Allocations

There Lxists a Set of Utility Functions That Render

These Decision Functions Not Effectively Computable

under Conditions of Perfect Information

rach Individual's Strategic Decision Process 
Perfect Information Is Not a Sufficient Condition for Pareto-Optimal Equilibrium Allocations

Moral Normative Constraints Are Necessary for Economically Efficient Outcomes of Market Interaction

Summary

4 A Spontaneous Order Objection

The Conflation of Classes of Situations by Hume.

Menger, and Hayek

Categorizing Types of Social Situations

The Requisite Normative Constraints Cannot Emerge within a Population of Strict Rational Egoists

Alternative Accounts of Spontaneous Order

Summary Discussion

5 The Roles of Mioral Normative Constraints in Relation to Externalitie,

Fxternality

The Roles of Moral Normative Comstraints in Achieving Economic Efficiency

6 The Moral Conditions of Ecomomic Efficiency 82

The Concept of a Normatic Social Practice 8.3

Rights in General $\quad 89$

Compliance 94

The Specific Moral Rights Required for Efficient Trade 99

A Synopsis of a St stem of Normative Conditions of

Efficient (Outcomes of Market Interaction

7 Implications

Concepts and Analytical Tools

Implications for Economic Theory

Implications for Political Theory and Moral Philosophy

Implications for Legal Theory

Summary and Concluding Comments

Notes

Bihliegraphy

Inderi 


\section{Preface and Acknowledgments}

I hope that this book contributes to a better understanding of the interconnection between morality and economic behavior. It is intended for those whose interests lie in legal theory, economic theory, moral philosophy, and political theory and for those who are concerned with ascertaining a moral basis for pluralistic, private property democracies. I also hope that the theoretical results of this work will prove useful to policy analysts, judges, legislators, and those involved in developing constitutions for emerging democracies.

Several perplexities, hunches, and heuristically fruitful concepts served to focus my interest in the moral conditions of economic efficiency. I first became interested in this issue while reading Adam Smith's Wealth of Nations and Theory of Moral Sentiments. It seemed to me then that there was a closer connection between morality and market behavior in Smith's writings than was made explicit. I am sympathetic to and inspired by what I believe is the intent of Jules Coleman's Risks and Wrongs and of David Gauthier's Morals by Agreement. A pluralistic democracy having a private property economy needs some common morality that respects a pluralism of moral traditions, is capable of guiding the common life of all, and underwrites its legal system. But, at the time, the relationship between morality and markets seemed to need greater clarification before competing traditions could come to any "agreement" or "rational choice contract." Since an overarching issue is social behavior, it seemed that some account of social behavior must be thrown into the mix as well. I found myself intrigued by Ludwig Wittgenstein's notion of a social practice but enlightened by Ronald Koshoshek's views of the same.

Musing over these perplexities, hunches, and concepts led to a closer examination of the presuppositions of the First Fundamental Theorem of Welfare I:conomacs (or l-irst Welfare Theorem), which is a precise version of Adam Smmh i m isible hand. Simplifying assumptions camnot be avoided in social serence. But sometimes It pays to reexamine those assumptions to see whether they can be expanded to cover other contributing lactors. The more I considered the assumptrons of the lirst Welfare Theorem and what they were sup- 
posed to accomplish, especially in view of Smith's moral theorizing and preEnlightenment views of property, the more I was drawn by the intuition that morality made economic efficiency possible for autonomous people.

I am grateful for the help I have received from several individuals. From Ronald Koshoshek I acquired the background framework of concepts for understanding social behavior that informed this project. Furthermore, his expert and forthright advice was instrumental in my being interested in moral rights and their relationship to economic analysis in the first place.

I am indebted to Daniel Johnson and William Thedinga for our weekly colloquium and for detailed written comments on several entire drafts. This work involves concepts and jargon germane to moral philosophy, economics, and law. There is always a risk of misunderstanding and misrepresentation when one adopts the specialized language of each these fields while addressing oneself to a problem common to all. Their sensitivity to the nuances of those languages and wonderful facility with correct English doubtlessly contributed greatly to the clarity of the finished project and to the accessibility of its ideas to non-experts. Any conceptual errors or stylistic oddities that occur in the manuscript are there because I ignored their advice.

For the uncompromising precision and thoroughness that Norman Dahl and Leonid Hurwicz showed in commenting on earlier drafts; for the intellectual stimulation and multidisciplinary expertise of Norman Bowie; and for the editorial comments, suggestions, and enthusiastic support of Peg Brewington, I am deeply grateful.

A Cedarville University Faculty Research Stipend enabled me to dedicate several months solely to this project.

But more than any, I thank my dear spouse and best friend, Mary, who in the operation of her business has always observed the moral normative constraints discussed herein, who has supported this project in countless ways, and who is happier than I am to see it finished. 
The Moral Conditions of Economic Efficiency 



\section{1 \\ Introduction and Synopsis}

This work is a rigorous analysis of the moral conditions of economic efficiency and these two central questions focus its argument:

Question 1. Can a population of strict rational egoists achiere' efficient allocations of commodities through market interaction in the absence of moral normative constraints.'

If not, then we must ask:

Question 2. What are the moral nomative comstraints and other types of normative conditions of market interaction leading to efficient ontcomes? 1

Adam Smith's so-called Invisible Hand Claim has been subject to two centuries of theorization that has intensified in the last two decades. Yet in this time we have not achieved any consensus on the possible moral conditions of economic efficiency. My analysis provides a way to frame the issues rigorously and to answer the two central questions.

The first question defines my first task: to determine whether economically efficient outcomes of market interaction require moral (in contradistinction to legal) normative constraints; that is, whether the constraints needed for efficiency are normative. moral, and rational. I will demonstrate that efficient outcomes of market interaction cannot be achieved without a system of moral normative constraints for securing competitive behavior and a set of conventions for taciliating exchange, for coordinating supply and demand, and for internalising certain types of externalities. After this is established, the second quesuon defines my second goal: to specify a set of nomative conditions that make efficient outcomes of trade possible.

Answers to these central yuestions affect not only basic concepts in economic theory but also fiedds for which economic analysis is important, includ- 
ing legal theory, moral philosophy, political theory, and policy analysis. ${ }^{2}$ The concepts - market, perfect competition, perfectly competitive market, externality, and the First Fundamental Theorem of Welfare Economics - are all affected by answers to these questions. Both moral philosophy and political theory gain by taking the concepts and techniques of economic analysis into consideration. Appeals court judges and policy analysts often use economic efficiency as a factor in their decisions and proposals. Since, as I will show, economic efficiency requires moral normative constraints, such decisions and proposals must not undercut the moral conditions of economic efficiency.

This analysis requires clarifying some central concepts and making appropriate distinctions where necessary. There are two types of normative conditions of efficiency: normative constraints and conventions. In general, a normative constraint is a limit on an agent's range of possible actions and is constituted by a behavioral rule and a sufficient incentive to comply. Normative constraints can be either proscriptive or prescriptive. I will say more about normative constraint in the next section by contrasting it with morality. A convention, on the other hand, could be described as a coordinating rule. A regularity in social behavior emerges when each individual observes a convention by virtue of an incentive given by instrumental (or practical) rationality alone. For example, the conventions of grammar guide the use of a common language and enable communication. Communication would fail without such conventions. Economically efficient outcomes of trade require both normative constraints and conventions.

I specify a set of normative conditions, which I demonstrate to be not only necessary but also sufficient in theory for efficient outcomes of trade. These normative conditions are moral in nature. And I will show that moral norms or rules alone are not sufficient. Some type of enforcement is also necessary. I show that the only such mechanism is an internal incentive to comply with rules. In the real world, moral norms are not perfectly observed. Where moral norms are violated in the real world due to such things as weakness of will, sociopathology, or a misunderstanding of the moral nature of trade, a legal system of some sort can supplement moral norms. However, a legal system by itself is not sufficient for efficiency. I will show that a legal system cannot replace moral normative constraints. Therefore, to the extent that the moral conditions I specify are not met, resources are wasted enforcing compliance and rectifying the results of non-compliance.

In spite of their importance, definite answers to these central questions much less any kind of consensus - have proved elusive ever since 1776 when Adam Smith in his book, An Inquiry Into the Nature and Causes of the Wealth of Nations, claimed that when each person pursues his or her own interests they are together led as if by an invisible hand to achieve the common good. Such an achievement requires conventions, but does it also require moral normative constraints? Smith (1776: 456$)$ writes, 
As every individual, therefore. endeavors as much as he can both to employ his capital in the support of domestic industry, and so to direct that industry that its produce may be of the greatest value: every individual necessarily labors to render the annual revenue of the society as great as he can. He generally, indeed neither intends to promote the public interest. nor knows how much he is promoting it. By preferring the support of domestic to that of foreign industry, he intends only his own security; and by directing that industry in such a manner as its produce may be of the greatest value, he intends only his own gain, and he is in this, as in many other cases, led by an invisible hand to promote an end which was no part of his intention [emphasis added].

It appears that it was not Smith's intention to determine whether, much less which moral normative constraints are required. However, it is certainly understandable that many have understood Smith to assert that, without moral normative constraints, as long as an economic agent "intends only his own security" and "only his own gain" (emphasis added) that agents will promote some type of common good. That is to say, it is understandable how the claim that legal or moral normative constraints are not necessary could be made on the grounds of Adam Smith's references to an "invisible hand." 3 However, Smith (1776:687) seems to suggest that there is a role for normative constraints in his "obvious and simple system of natural liberty." "Natural liberty" is defined by the absence of governmental interference and by a proviso: "as long as he does not violate the law's of justice [emphasis added], [every man] is left perfectly free to pursue his own interest his own way, and to bring both his industry and capital into competition with those of any other man, or order of men." Nevertheless, Smith does not here indicate what he means by "the laws of justice." Nor does he even mention them until Book IV, Chapter IX, far removed from his invisible-hand statement. In his earlier work, Lectures on Jurisprudence (1763: 7). Smith writes,

The first and chief design of all civill [sic] governments, is, as I observed, to preserve justice amongst the members of the state and prevent all incroachments [sic] on the individualls / sic $\}$ in it, from others of the same society. - \{ That is, to maintain each individual in his perfect rights.)

Smith divides the set of "perfect rights" into two subsets: natural rights and acquired rights. Natural rights are rights persons hold by virtue of being persons. Natural rights are moral rights. Acquired rights are rights held by virtue of citizenship. Nevertheless, even acquired rights have their basis in morality. Smith (1763: 401 ) refers to his A Theory of Moral Sentiments in his account of the origin of the state to its ground in moral psychology. Thus, for Smith, the "laws of justice" are moral presuppositions of positive law.

Nevertheless, Smith does not show whether or how morality affects the workings of the Invisible Hand. It appears that Smith himself may have recognised that the role of normative constraints in his "system of natural liberty" 
was not adequately developed in either the first edition of the Wealth of Nations or in the earlier $A$ Theory of Moral Sentiments, for he spent the last years of his life revising these works to show how the invisible hand is insufficient without morality. ${ }^{4}$ I have dealt at length with Adam Smith because it seems that the lack of clarity regarding answers to our central questions can be traced back at least that far.

Contemporary writers who advert to Adam Smith likewise are unclear about the role and specifics of normative constraints for efficient outcomes of market interaction. I am not suggesting that Smith and those who refer to him were attempting to determine whether and which normative constraints are required for efficient outcomes of market interaction. I am drawing attention to how an understanding that efficient outcomes of trade do not require moral normative constraints could be drawn from Smith and others. Consider the account given by Friedman:

Adam Smith's flash of genius was his recognition that the prices that emerged from voluntary transactions between buyers and sellers - for short, in a free market - could coordinate the activity of millions of people, each seeking his own interest, in such a way as to make everyone better off. It was a startling idea then, and it remains one today, that economic order can emerge as the unintended consequences of the actions of many people, each seeking his own interest. (1980:13-4)

It is not clear whether Friedman thinks normative constraints are essential for economically efficient allocations of commodities. The closest Friedman comes to citing anything like normative constraints is the idea that transactions must be voluntary. The concept of voluntary exchange is essential in depicting efficient outcomes of trade, but Friedman does not specify what he means by the term "voluntary." Friedman indicates that voluntariness should be seen primarily as a lack of State coercion - even though he once mentions that robbery is a type of coercion, and once he indicates that people may be coerced by invaders from other nations. But Friedman does not indicate which specific types of normative constraints are required to preclude these kinds of detrimental actions and to ensure that exchanges are voluntary. In all fairness to Friedman, I must reiterate that it is not his explicit intention to specify both the exact meaning of voluntariness and what specific kinds of constraints voluntariness implies. ${ }^{5}$ The point is simply that Friedman is not clear regarding both the role and the specific kinds of normative constraints in market interaction. His lack of clarity may depend upon the lack of clarity regarding the notion of a voluntary exchange.

Furthermore, few if any proofs of the First Fundamental Theorem of Welfare Economics (which is commonly understood to be a proof of the Invisible Hand Claim) explicitly indicate the types and role of a system of normative conditions whose effects they presuppose. Furthermore, the First Welfare Theorem along with its assumptions regarding agents has served as a point of departure 
for legal theory, economic analysis, and moral philosophy in the last two decades of the twentieth century. We have gotten this far in our theorizing without first having achieved some kind of consensus on the moral conditions of economic efficiency.

\section{Morality, Moral Rules, and Normative Constraints}

There is also a persistent lack of clarity and of consensus among scholars in philosophy, in economics, and in legal theory regarding some concepts crucial to the central questions we face. Thus, to answer our central questions with sufficient precision, I must stipulate my use of essential terms.

At this point, the concepts of morality and of a normative constraint must be differentiated. In this book, morality is understood to be a normative social practice, which is a social phenomenon - a regularity in social behavior - (1) guided by beliefs held in common concerning (a) the criteria by which a group of individuals evaluate their own and others' behavior and according to which criteria they hold each other responsible and (b) the procedures for holding each other responsible, and (2) the purpose of which is directly pertinent to individuals' well-being taken individually and collectively.

The criteria that guide a morality can be rules, norms, or even simple expectations. I use the terms interchangeably even though there are conceptual differences. A person may expect, for instance, that others will not engage in some kinds of behavior, yet it may never have occurred to her to view her expectation as being expressible by rule guiding the behavior of others. Only the notion of criteria guiding behavior is primary. How those criteria themselves are conceptualized is not essential to my argument.

What makes a rule a moral rule is partially a matter of its function in achieving and sustaining well-being through a social practice, where the content of a conception of well-being is dependent on the commonly held beliefs of its correlative community's members. ${ }^{6}$ Generally speaking, a particular community 's concept of well-being depends on what that community values and how it understands reality, human beings, and the cause of thwarted ideals. Accordingly, to understand the rationale for a moral rule is to understand its relation to these beliefs and to the conception of well-being associated with them.

Furthermore, since a norm, rule, or expectation is moral due to its function in securing a conception of well-being, it follows that what some groups take to be merely a standard of etiquette, others may understand morally - as functioning, that is, to secure well-being. Similarly, what some groups understand to be both legal and moral. others may understand to be legal but not moral. such as the Nuremberg laws in Nazi Germany or the Apartheid laws in pre-democratic South Africa. Further, an obligation to obey the law may be understood by some groups as a moral obligation. ()thers might believe that a so-called obligation to obey the law is a conceptual mistake or even a redundant ${ }^{7}$ legal but 
not moral obligation. In short, the moral is whatever a particular group sees as such.

Kant's rationale which is supposed to distinguish a rule of morality from a rule of prudence, is an a priori demonstration. But perhaps the differences among a convention, a prudential rule of thumb, and a moral rule are better determined by reference to the types of grounds cited in a rationale. For example, a request for a rationale for a particular convention might elicit the following response:

"That's just the way we do it, that's all. Probably no one knows why."

A rationale for a rule of prudence might go like this:

"If you want to achieve $\mathrm{Y}$, everyone knows that doing $\mathrm{X}$ is the only or the best way."

A rationale for a moral rule might, on reflection, refer the interlocutor to what has value, or some feature of human nature.

This account of the moral takes the fact of cultural relativism into consideration. Moralities and their criteria are socially constructed. However, to say that such criteria are socially constructed is not to deny what some groups and traditions hold to be essential about their moral norms. It is not to deny, that is, that their moral rules are either natural laws or God-ordained. It is logically possible that these claims could be true. If so, then the particular social practice guided by such rules is historically situated and takes on the nuances of that situation. Cultural relativism does not imply cognitive relativism.

To reiterate, morality is a social practice guided by moral rules, which in turn are identified as such by virtue of how compliance achieves and sustains communally defined well-being. How, then, does morality and moral rule relate to normative constraint? In the most general sense, a constraint is some device that effectively inhibits some type of action from occurring. In economic models of market interaction, agents typically face two kinds of constraints: positive constraints and normative constraints. ${ }^{8}$

Positive constraints delimit a set of physically possible actions. For example, the value of the set of commodities an agent presently holds is her budget constraint. Its value (given in terms of an exchange ratio with other commodities) sets a limit on alternative sets of commodities for which it can be traded. For a simplified example, if Alice has two fish and the value of one fish is either two loaves of bread or one basket of fruit, Alice may trade her fish for four loaves of bread, for two baskets of fruit, or for two loaves of bread and one basket of fruit - but no more. Even though - as we shall see in Chapter 2 -agents in this model prefer a set of commodities having a higher value than the value of the set they presently hold, they cannot purchase such a set. That is, they are 
positively (or, objectively) prevented from taking an action not because of an enforced rule, but by virtue of a constraint they are powerless to violate.

In contrast, normative constraints constitute a broad class of all nonpositive constraints. Normative constraints limit an agent's range of possible actions and are constituted by a norm and a sufficient incentive to comply. Normative constraints involve rules, norms, or behavioral expectations held in common by a group of people, but a normative constraint must be distinguished from a rule, norm, and expectation. A rule proscribing some type of action is not, by itself, a normative constraint. A rule merely expresses a proscription or prescription of some sort. A linguistic expression of a prohibition is not sufficient by itself to preclude the prohibited action. Likewise, merely understanding that certain types of behaviors are required or prohibited is not sufficient to ensure the required behavior or to prevent proscribed behaviors. To have an effect on behavior, a rule must be supplemented (enforced if you will) with a sufficient incentive to comply. In other words, only if a rule is enforced by some mechanism will it have any effect on behavior. An enforcement mechanism supplies an incentive that renders undesirable any action contrary to the rule, thereby inhibiting its occurrence. So, in general, an individual is normatively constrained if and only if she has a sufficient incentive to observe some rule, norm, or behavioral expectation.

Perhaps the following four examples will add more clarity to the concept. First, an individual is normatively constrained if a dictator commands a certain action and enforces it by a threat regarding which the individual has aversive desires, and the individual believes that violations can always be detected. Let the incentive be referred to as an external incentive. Second, an individual is normatively constrained if a legal system proscribes a certain action and enforces it by threats of incarceration or fines regarding which the individual has aversive desires, and the individual believes that violations can always be detected. Again, the individual is normatively constrained by a rule and a sufficient external incentive. Third, an individual is normatively constrained if some moral principle requires some action regarding which the individual has aversive desires, but she values the social "fabric" that the principle preserves over her aversions. In this case the rule is "enforced" by her value for what the rule protects. The incentive in this example is an internal incentive. Finally, an individual is normatively constrained if he observes a rule for no reason other than for duty, or for what he believes about the intrinsic value of following the rules. In these last two cases individuals have an internal incentive to follow the rules, and therefore, in this sense, the rules can be said to be enforced. The point here is to clarify the idea that a normative constraint is constituted by a rule (of some type) and either by an external or by a sufficient internal incentive.

Admittedly, the distinction between intermal and external incentives is not as precise as it could be. A deeper analysis would show that the intended references of each have both internal and external components. However, for the pur- 
poses of answering the two central questions of this book, we need only distinguish between incentives that are purely selfish and those that are not. A purely selfish individual is motivated only to achieve (avoid) his own gain (loss) and to maintain his ability to do so. His gain (loss) is defined solely in terms of his preferences for commodities. A purely selfish agent does not care about the relative satisfaction of others' preferences, much less anything about their relative abilities to lead satisfying lives. By contrast, a non-purely selfish individual cares about others to some degree and the social practices that contribute to their well-being. In this book, purely selfish agents respond to external incentives only, not to internal incentives. I argue that economically efficient outcomes of trade require, among other things, that agents possess internal incentives to comply with a set of moral rules. In this sense, economically efficient outcomes of trade require morality.

In the theoretical model presented in this book, normative constraints are effective because incentives are viewed as always being sufficient. Idealized agents who recognize rules and are universally subject to sufficient motivations can be construed to act in accordance with the rules, even though less than ideal agents may not.

Defining normative constraint in this way entails not only that a rule and some sufficient incentive are necessary, but that they are also sufficient. It may seem that this makes the notion of being normatively constrained a non-normative concept. But it does not. A normative constraint is defined in this book as nonpositive, or non-objective. Recall that a positive, or objective, constraint is a limitation on the set of possible actions about which the agent has no choice regardless of her dispositions or desires. On the other hand, a sufficient incentive depends only on an agent's disposition or desires. Had they been different than they are, the agent could have chosen the alternative course of action. This is exemplified by those people who are naturally disposed to take actions or refrain from actions that norms happen to require or to prohibit. Such norms simply describe their patterns of behavior. From their perspective, they do not feel constrained.

Normative constraints define an agent's admissible strategy domain. Let me explain. The set of actions that are physically possible for an agent is his natural strategy domain. The term, natural strategy domain, is standard in economics and game theory. But not every physically possible action is rational. Since agents are presumed to be instrumentally rational, the normative constraints of practical reason restrict agents' natural strategy domains and delimit their rational strategy domains. In other words, an agent's rational strategy domain is a subset of his or her natural strategy domain. Normative constraints and conventions further restrict individuals' natural strategy domains -and delimit agents' admissible strategy domains.

Since an agent's admissible strategy domain is a proper subset of an agent's rational strategy domain, every admissible strategy is also a rational strategy. 
Thus, every normative constraint and convention in our model is individually rational. Furthermore, since what makes a rule a moral rule is partially a matter of its function in achieving and sustaining some concept of well-being based on the control beliefs of a given community, moral normative constraints are also collectively rational. I will show that a perfectly competitive market is a normative framework for trade that secures perfect competition and, therefore, is constituted by a set of rational constraints on the pursuit of self-interest.

But the moral rights of a perfectly competitive market are also collectively rational. They result from collective reasoning about goals. There are at least tw'o types of goals. The first type is a completed achievement such as winning the World Series. The second type involves achieving and sustaining some kind of condition. such as getting physically fit. The goal of creating a set of rules to ensure efficient outcomes of market interaction is of the second type. It could go like this:

Premise: We desire to achieve and maintain conditions that ensure economic efficiency.

Premise: Actions of type A undercut our goal, and actions of type B are required.

Conclusion: Therefore, none of us should take an action of type A. which undercuts our goal, and all of us should take actions of type B. which are required.

This piece of reasoning is collectively rational. Even though the question of the rationality of moral constraints in general is thus closely related to central issues in this book, it lies beyond its scope. Nevertheless, since the goal of this book is to specify a system of normative conditions that make efficient outcomes of trade possible, the individual and collective rationality of moral normative constraints is also established.

In sum, morality is a normative social practice, moral rules guide such practices, and a moral normative constraint is a limitation on an agent's range of possible actions and is constituted by a moral rule and a sufficient internal incentive to comply with such norms. Such constraints are both individually and collectively rational.

\section{Synopsis of the Book}

In (hapter 2, I develop the theoretical setting required to answer both central questions. I first construct a framework for analy framework is composed of two divisions corresponding to the two essential aspecis of social situations. The first division regards agents; the second, the Situation in which they interact. Agents are depicted in terms of their preferences and there rationality. The Situation within which agents act is defined in terms 
of positive and normative conditions. Each of the four subcategories (i.e., preferences, rationality, positive conditions, normative conditions) involves at least two variable assumptions. Alternative social situations are, therefore, specified within this framework by variously altering one or more of nine variable assumptions.

By the particular content given to assumptions $\left(\mathrm{p}_{1}\right)-\left(\mathrm{p}_{5}\right)$, I then specify a particular type of social situation in which agents, who are purely selfish and fully rational, interact in the absence of moral normative constraints; that is, they interact under pure anarchy. I call this particular type of social situation Strict Rational Egoism. I have added the adjective, strict, to rational egoism to modify egoism so as to indicate pure selfishness in contradistinction to the common term rational egoism, which allows altruistic desires and behaviors.

To determine whether moral normative constraints are necessary conditions of efficient outcomes of trade, descriptions of agents must not involve morality in any way, and interaction among agents must not be affected by any morally relevant factors. Thus, for example, such agents must be defined so as to exclude the effects of morally significant constraints such as those attributable to the internalization of moral norms. Therefore, I develop the concept strict rational egoist as a purely selfish agent rather than begin with rational egoists, who are agents who may have preferences that some may view as moral. By specifying the variable assumptions in the framework, I depict Strict Rational Egoism, which is, therefore, a type of social situation in which every agent is a strict rational egoist. A principle of action is derived from Strict Rational Egoism and expresses the necessary and sufficient conditions under which a strict rational egoist will take action.

Notice that I am not attempting to describe or to model actual human behavior. I am modeling the behavior of idealized agents. I show that the absolutely, nonnormatively constrained interaction of such fictitious agents cannot achieve efficient outcomes of trade. Then, I determine at least one set of normative conditions just sufficient to achieve such outcomes. These conditions include a set of moral rules and a change in the agents themselves, which provides internal incentives to comply with the rules. Such incentives are not matters of practical rationality grounded in pure selfishness. They are matters of practical rationality grounded partially, for example, in value for others' wellbeing or for the social fabric of their lives. ${ }^{10}$

Finally, I further develop the theoretical setting by examining the fact that the presuppositions of the First Fundamental Theorem of Welfare Economics (or First Welfare Theorem) are not the assumptions of Strict Rational Egoism. That is, alternative proofs of the First Welfare Theorem assume either that competitive behavior exists without also indicating the mechanism that ensures it or that the conditions of a perfectly competitive market preclude efficiency-reducing actions. In addition, alternative proofs of the First Welfare Theorem assume the absence of externalities; that is, they assume that there are no inten- 
tional, incidental, or accidental effects on the well-being of a consumer or the production possibilities of a firm not accounted for by the inarket mechanism. ${ }^{11}$ Thus, intentional, incidental, and accidental adverse effects on efficiency are presumed not to occur because the actions that cause them are assumed not to be taken. But such effects of agents' actions are not ruled out under Strict Rational Egoism. That is, Strict Rational Egoism does not preclude the possibility of actions being taken that adversely affect the efficiency of outcomes of trade. It does not matter whether such effects are either intentional, incidental, or accidental.

The incompatibility between what the First Welfare Theorem assumes and what Strict Rational Egoism allows points to the ambiguity regarding the role of moral normative constraints in the First Welfare Theorem and underscores the need to examine the role of moral normative constraints. ${ }^{12}$ Proofs of the First Fundamental Theorem of Welfare Economics show that under certain conditions every equilibrium allocation of commodities is efficient. But the central question is this: Must those conditions include moral normative constraints?' If so, then the First Welfare Theorem is not a proof of the common understanding of Adam Smith's claim regarding the Invisible Hand.

By paying close attention to the conditions under which the proof succeeds and by comparing these assumptions to what Strict Rational Egoism allows, we are in a position to determine under what conditions purely selfish agents will engage in trade and achieve efficient outcomes and, thus, to specify the role of morality in the First Welfare Theorem. In versions of the First Welfare Theorem. morality appears to have no role because the actions it precludes are either presumed never to be chosen or else prevented by nonnormative factors. This book clarifies the role and types of normative conditions that the First Welfare Theorem and, by implication, the Invisible Hand Claim presuppose.

In Chapter 3, I make the first of three claims that jointly constitute a response to the first question: Can a population of strict rational egoists achieve efficient allocations of commodities through market interaction in the absence of moral normative constraints? On the basis of the specified assumptions of the framework for analyzing social situations, I show that a population of strict rational egoisls cannot achieve efficient allocations in the absence of moral normative constraints because moral normative constraints are necessary conditions of competitive behavior. In Chapters 4 and 5 , I strengthen the claim by showing that (1) strict rational egoists have no moral incentives to comply with whatever rules are agreed upon and (2) no means exist for internalizing externalities.

There are three reasons why moral normative constraints are necessary conditions. First, a presumption against nommarket action entails a contradiction. Second, under a widely accepted conception of a "perfectly competitive market." Indiv iduals have both an incentive and the means to violate the rules of the process. Theretore, given the derived principle for action (DPA), agents will not behave competstively, finally, even if we alter assumptions $\left(p_{5}\right)$ and $\left(p_{6}\right)$ so 
that agents have maximal information-processing capabilities and perfect information regarding every economically relevant variable, the possibility exists that no agents will be able to make a decision. In particular, I show that there exists a set of decision functions which are not effectively computable. This section is technical, and the reader may wish to skip to the section summary. Thus, the answer to the first question is that a population of strict rational egoists cannot achieve efficient allocations in the absence of moral normative constraints.

In Chapter 4, I strengthen the result by showing that strict rational egoists will not comply with whatever rules are agreed upon. We proceed by way of a response to a possible objection. A spontaneous order objection might be raised against the conclusion of Chapter 3. claiming that the social behavior of selfish individuals in a situation depicted by the specified assumptions of the framework will converge into regular patterns, which, in turn, will be sufficient to produce optimal outcomes of trade. It is important to bear in mind that this is not a denial of the claim that some type of moral normative constraints are necessary conditions of Pareto efficiency. The Spontaneous Order Objection assumes that moral normative constraints are necessary. Rather, it denies that Pareto-optimal equilibrium allocations are not achievable for strict rational egoists in a social situation defined by premises $\left(p_{1}\right)-\left(p_{9}\right)$.

In response to the objection, a rigorous distinction between coordination situations and collective action situations is made, and the role of convention is further developed. We see that conventions are not normative constraints. Furthermore, only moral normative constraints - partially constituted by collective action rules - can converge agents strategies in collective action situations.

Premises $\left(p_{1}\right)-\left(p_{x}\right)$ define an exchange situation, which is show'n to be a collective action situation. After discussing five types of possible solutions to collective action situations. I show that the Spontaneous Order Objection holds only if there is a solution to an exchange situation that arises only from premises $\left(p_{1}\right)-\left(p_{x}\right)$ : that is. only if any of the five solutions are internal solutions.

In short. strict rational egoists will not comply with rules because exchange situations are collective action situations. and of the five possible types of solutions to collective action situations. none will be adopted by strict rational egoists. Therefore, the Spontaneous Order Objection fails.

In Chapter 5. I augment the claim that a population of strict rational egoists cammot achieve efficient allocations of commodities through trade by showing that, in the absence of moral normative constraints, no means exist for internalizing externalities. The proof of the First Welfare Theorem implicitly assumes that externalities are absent. Assuming that externalities are absent - just as assuming that every agent behaves competitively - sets the question of the role of normative constraints aside. I first clarify the term evernality and distinguish between intentional, accidental, and incidental externalities. I show (1) how a specified system of moral normative constraints and procedures (conventions) can secure competitive behavior and can preclude or rectify the ef- 
fects of the three types of externalities, (2) how moral normative constraints converge expectations and thereby reduce transaction costs, and (3) that moral normative constraints provide logical limits of the commodification of desire. I conclude that since (1) without moral normative constraints, externalities cannot be precluded, much less rectified, (2) that expectations will not converge, and (3) without limits on what kinds of things can be commodified, economic efficiency is not possible for strict rational egoists.

In Chapter 6, I respond to the second question: What are the moral normative constraints and other normative conditions of market interaction leading to efficient outcomes of trade? The normative presuppositions of market interaction leading to efficient outcomes include a system of moral normative constraints, a set of conventions for equilibrating supply and demand, and a set of moral normative constraints and conventions for internalizing intentional, accidental, and incidental externalities. The system of moral normative constraints is specified as a normative social practice in which

(i) a set of moral rights - construed as a set of moral Hohfeldian positions that restrict agents' natural and rational strategy domains - provides a moral basis for internalizing externalities,

(ii) each agent has some sufficient internal incentive to comply with these rights, and

(iii) there exists a set of procedures according to which agents hold each other responsible.

Together, the system and the conventions constitute one set of background presuppositions of the First Fundamental Theorem of Welfare Economics.

In Chapter 7, I reiterate and explore the implications of the results for moral philosophy, economics, legal theory, and political theory. In particular I explore and defend the following claims:

\section{Economic Theory}

1. A market is an institution and perfect competition is a type of social interaction secured by a set of normative conditions, which include moral normative constraints and which internalize externalities. A distinction should be maintained between intentional, incidental, and accidental externalities, which are the effects of actions not governed by normative conditions. It follows that a perfectly competitive market includes a set of moral normative constraints and that any proof of the First Welfare Theorem presupposes this general set of normative conditions.

\section{P'olitical teconom! and Moral Philosophy"}

2. I he Invsible Hand (laim is mistaken: agents pursuing their interests must also possess mernal incentives to comply with a particular set of moral norms to acheve their 'common good'. 


\section{Legal Theory}

3. Appellate decisions based on economic efficiency must not ignore the moral rights, which are efficiency's necessary conditions.

4. The moral conditions of economic efficiency set moral and logical limits on the commodification of desire. 